\title{
A RARE CASE REPORT OF SYNCHRONOUS MALIGNANCY - SQUAMOUS CELL CARCINOMA OF BASE OF TONGUE AND ADENO CARCINOMA OF STOMACH
}

\author{
Prakash S. B' , Leelatejaswini R. M², Veenapani M. K³, Geetha C4, Nishaan ${ }^{5}$
}

\section{HOW TO CITE THIS ARTICLE:}

Prakash S. B, Leelatejaswini R. M, Veenapani M. K, Geetha C, Nishaan, "A Rare Case Report of Synchronous Malignancy - Squamous Cell Carcinoma of Base of Tongue and Adeno Carcinoma of Stomach". Journal of Evolution of Medical and Dental Sciences 2014; Vol. 3, Issue 59, November 06; Page: 13338-13342,

DOI: $10.14260 /$ jemds/2014/3777

\begin{abstract}
The synchronous occurrence of primary squamous cell carcinoma of base of tongue with gastric adenocarcinoma is very rare. We report a case of 50 year old male patient presented to ENT OPD with complaints of throat pain, painful swallowing since 1 month. Indirect laryngoscopy showed ulceroproliferative growth in Base of tongue, vallecula and epiglottis. Upper GI endoscopy showed ulceroproloferative lesion involving base of tongue, left epiglottis and vallecula. Endoscopic Biopsy from the growth revealed squamous cell carcinoma of the base of the tongue and adeno carcinoma of the stomach. We report this case to highlight a rare occurrence of synchronous malignancy of posterior tongue and stomach.
\end{abstract}

KEYWORDS: Multiple primary tumors, panendoscopy, head and neck, squamous cell carcinoma.

INTRODUCTION: Approximately 70\% of oropharyngeal cancers are squamous cell carcinoma. Oropharyngeal squamous cell carcinoma is said to represent $10-15 \%$ of all head and neck tumor. There is an increasing prevalence of oral cavity and oropharyngeal carcinoma in last decade, particularly in men aged 35-64 year. More common in men with sex ratio 4:1, in $6^{\text {th }} \mathrm{n} 7^{\text {th }}$ decades. ${ }^{1,3}$ Tumor at tongue base rarely produce any symptoms and are not easy to detect. Consequently, the overwhelming majority of such patients have locally advanced tumors when they present.

CASE REPORT: A 50 year old male patient presented with complaints of throat pain, difficulty in swallowing of 1 month duration. Patient is smoker and alcoholic since 30 years. He also gave history of loss of appetite and weight loss. On ENT examination there is presence of nicotine stain in buccal mucosa. Indirect laryngoscopy showed ulceroproliferative growth in base of tongue, left vallecula and left supraglottis. Vocal cords were not visible. There was no significant lymphadenopathy.

Biochemical Investigations reports of blood and urine were within normal limits.

\section{Upper GI endoscopy Shows:}

1. Ulceroproliferative growth involving base of tongue, left epiglottis and vallecula.

2. Chronic gastric ulcer in the gastric antrum.

3. Biopsy was taken from both lesions. 


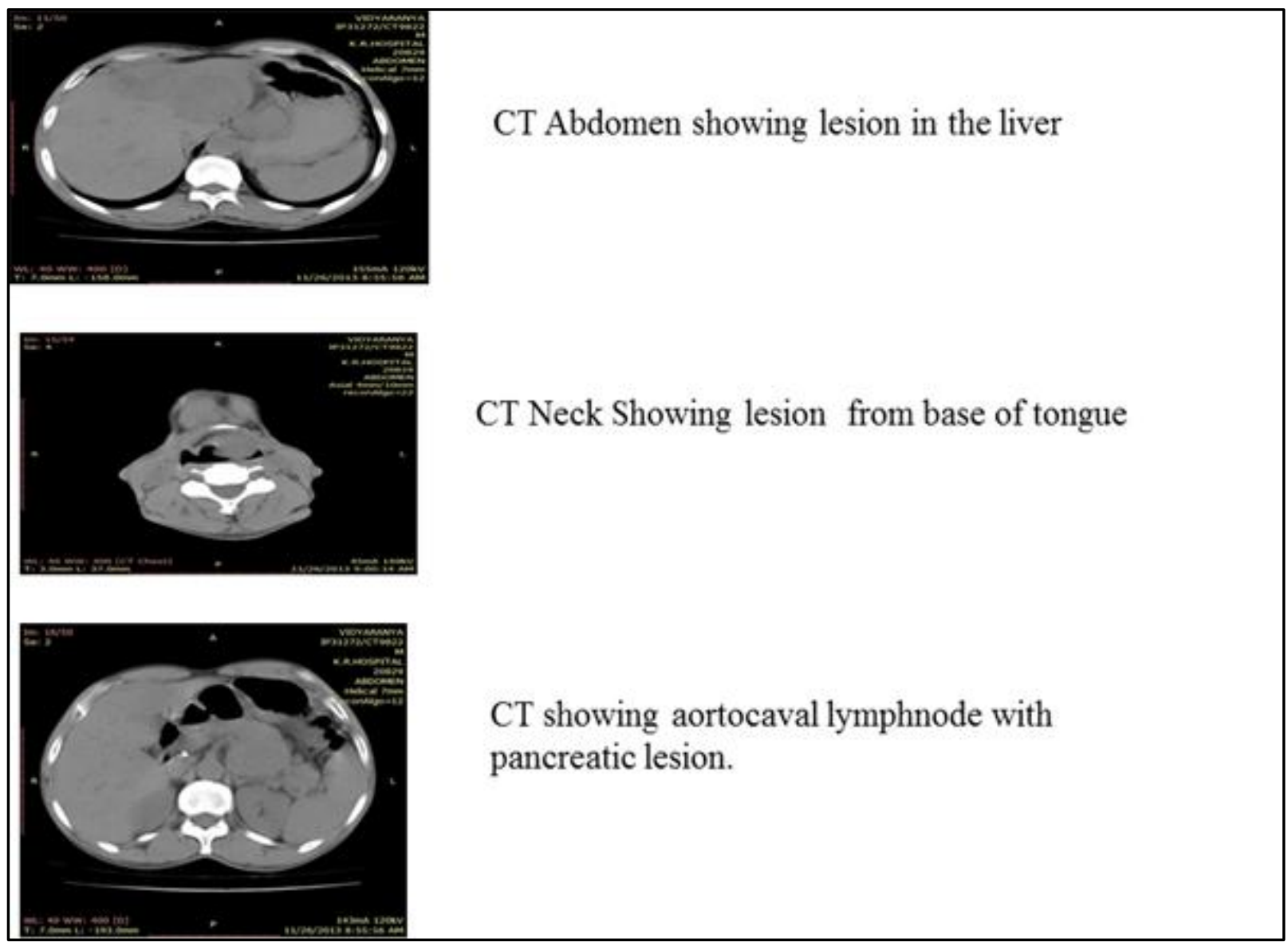

\section{Biopsy revealed:}

1. 1st Specimen showed tumor tissue with features of an infiltrating moderately differentiated squamous cell carcinoma.

2. 2nd specimen showed bits of gastric mucosa and tumor tissue with features of moderately diffrenciated adeno carcinoma.

In a view of evaluating clinically missed neck nodes CT scan neck (plain and contrast) was done which revealed enhancing isodense mass lesion measuring $34 \times 30 \times 26 \mathrm{~mm}$ arising from base of tongue with extending inferior to involve the left valecula and epiglottis. Lesion is seen to involve the left aryepiglottic fold and left pyriform sinus. There was no neck node metastasis.

In view of evaluating metastasis from gastric carcinoma CT abdomen (plain, IV \& oral contrast)revealed stomach thickness of $12 \mathrm{~mm}$, Liver showed 2 hypodense lesion in left lobe of segment II,III measuring 43x53x53mm and in segment IV measuring 45x57x43mm. Body of pancreas showed hypodense lesion measuring $72 \times 55 \times 45 \mathrm{~mm}$. Aortocaval lymph node measuring about $11 \times 6 \mathrm{~mm}$ was seen. 


\section{Endoscopic pictures:}

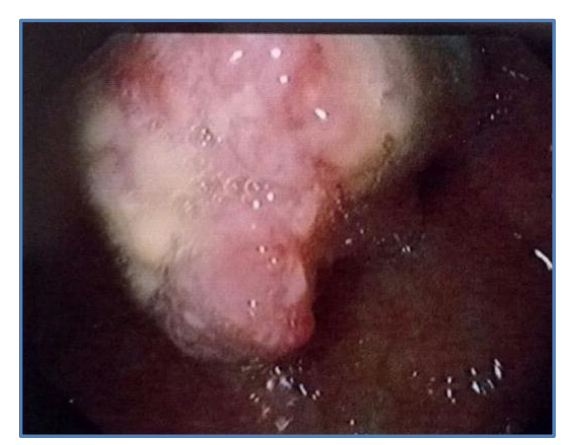

\section{An ulceroproliferative Supraglottic growth}

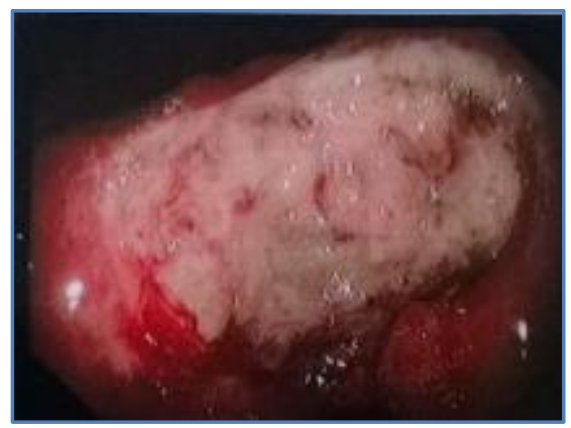

Gastric Antrum- Lesion

TNM staging of above growths is T4ANoMX Stage 4A of Oropharyngeal carcinoma. T4N1M1 Stage $4 \mathrm{~A}$ of gastric antral adenocarcinoma.

In view of extensive lesion of base of the tongue, supraglottis, hypopharynx CTRT Chemotherapy and radiotherapy was advised. The surgical treatment could be hemiglossectomy, total laryngectomy and hypopharyngectomy with reconstruction and tracheostomy. However the patient was not fit for the surgery.

In view of extensive hepatic, pancreatic and aortocaval lymph node metastasis no surgical option was considered for ca stomach. Patient was advised chemoradiotherapy. Palliative treatment was advised.

DISCUSSION: In recent decades multiple primary cancers in one patient is not uncommon. Second neoplasm are classified as 'synchronous, defined as occurrence of index tumor and second malignancy within 6 months of each other. ${ }^{1}$

In conclusion our case highlights a rare occurrence of synchronous double malignancy consisting of oropharyngeal squamous carcinoma and gastric adeno carcinoma. The first incidence of multiple tumors in a patient was reported by Billroth in 1889.' However, it was not until 1932, after Warren and Gates presented a review on multiple primary tumors that more attention was drawn to the subject.1,2 
A detailed history, including tobacco use and alcohol consumption, should be taken and a detailed examination with mirror and flexible fiberoptic endoscopy of the pharynx and larynx and a chest radiograph should be performed. For carcinoma of the oral cavity, oropharynx, hypopharynx, and larynx panendoscopy is mandatory (laryngoscopy, rigid bronchoscopy, esophagoscopy, and nasopharyngoscopic examination) at the time of evaluation and biopsy of the primary malignant lesion with the patient under general anesthesia. ${ }^{3}$

In addition, barium swallow examinations were performed for patients with symptoms suggestive of esophageal disease. CT, MRI, PET and SPECT should be done.

The tumor prompting specialist attention is termed as "index tumor," and synchronous tumors are defined as all additional tumors found at the same time or discovered within 6 months of the diagnosis of the index tumor and second primary tumors met the criteria as defined by Warren and Gates ${ }^{1}$ :

1. Each lesion was distinct, separated by normal tissue.

2. Each malignant lesion was confirmed by histologic examination.

3. The possibility of metastatic disease was excluded.

4. Lung lesions termed "second primary" were solitary and histologically distinct from the primary cancer examination.

Any second primary tumor found more than 6months after the discovery of the index tumor was termed a metachronous tumor. Follow-up assessments should be performed monthly for 3 months and every 3 months afterward.

The concept of field cancerization or "condemned mucosa syndrome" is the most popular theory put forward to explain the development of multiple cancers. ${ }^{1}$ This concept, used to explain the high local recurrence rate of oral cancer, also is applicable to the high rate of multiples synchronous primary lesions in the upper aerodigestive tract. Carcinoma of other distant sites and specifically those arising from the nasal cavity, salivary glands, orbit, lacrimal apparatus, skin of the lips, thyroid, and stomach should be ruled out.

These tumors are believed to have an etiology different from those oropharyngeal /laryngeal/esophageal tumors, which are mucosal in origin and exposed to similar irritants, e.g. tobacco20 cigars $^{1}$ a day and alcohol 37g.1,3 () Laryngeal cancer accounted for $38.4 \%$ of all head and neck. Patients who developed a second primary tumor tended to have a lower tumor stage (TI and T2). The average age of patients with multiple versus single lesions is greater at the time of diagnosis by 3 to 4 . The sex ratio of 4 to 1 for male to female is seen. ${ }^{3,4,5}$

For the above case the treatment option could be CTRT (Chemo therapy and radio therapy) for oropharyngeal carcinoma. As palliative treatment for adeno carcinoma of gastric antrum anterior Gastro jejunostomy with chemo therapy should be given. ${ }^{6}$

In conclusion, patients with head or neck squamous cell carcinomas shown that the esophagus, gastric carcinoma is the site with the highest risk of developing a synchronous second primary tumor in patients with head or neck carcinoma, particularly those with laryngeal carcinoma.

Lung second primary tumors are less common, and in contrast to Western experience, oral cavity and pharyngeal second primary tumors appear to be rare. This study emphasizes the importance of esophagoscopy in the initial assessment of a patient with head or neck malignant lesions. 
A diagnosis of metachronous malignancy calls for surgical intervention. In many instances, it is possible to perform radical surgery. The 5-year survival rate was 66.5\%in patients with metachronous malignancy who had undergone curative surgery; this rate was similar to that obtained in patients with synchronous malignancy.

Based on these findings, we suggest that it is important to do Careful pre- and intraoperative examination which may make it possible to reduce the incidence of so-called metachronous malignancy.

\section{REFERENCES:}

1. Alexander T K C, Andrew C V C, Elliot M C, Stuart R W, Walter W K K, Arthur K C. Multiple Primary Cancers in Hong Kong Chinese Patients with Squamous Cell Cancer of the Head or Neck. Cancer.1992 Aug 15:70(4): 815- 20.

2. Frederick Mc G, Brian M, James A K. Multiple Simultaneous Tumors in Patients with Head and Neck Cancer. Cancer.1982sept15: 50:1195-1199.

3. Watkinson J C, Gaze M N, Wilson J A. Stell and Maran's Head and Neck Surgery. Fourth Edition.

4. Jatin P S. American Cancer Society Atlas of Clinical Oncology Cancer of the Head and Neck.2001

5. Micheal Gleeson, Gearge G Browning, Martin J Burton, Ray Clarke, John Hibbert, Nicholars S Jones, Scott Brown , 7th edition, 2008, p2589.

6. Norman S, William's, Christopher J. K. Bulstrode, D. Ranon. O Connell, Bailey \& Love. 25 edition, p 1071-1073.

\section{AUTHORS:}

1. Prakash S. B.

2. Leelatejaswini R. M.

3. Veenapani M. K.

4. Geetha C.

5. Nishaan

\section{PARTICULARS OF CONTRIBUTORS:}

1. Assistant Professor, Department of ENT, Mysore Medical College \& Research Center.

2. Senior Resident, Department of ENT, Mysore Medical College \& Research Center.

3. Professor, Department of ENT, Mysore Medical College \& Research Center.

4. Post Graduate, Department of ENT, Mysore Medical College \& Research Center.
5. Post Graduate, Department of ENT, Mysore Medical College \& Research Center.

\section{NAME ADDRESS EMAIL ID OF THE} CORRESPONDING AUTHOR:

Dr. Leelatejaswini R. M, MIG-9, $2^{\text {nd }}$ Stage,

Kuvempunagar,

Mysore.

Email: drteju_drteju@rediffmail.com

Date of Submission: 24/07/2014.

Date of Peer Review: 25/07/2014.

Date of Acceptance: 05/08/2014.

Date of Publishing: 06/11/2014. 